\title{
Strategi Pengendalian Alih Fungsi Lahan Sawah di Provinsi Jawa Timur
}

\author{
Fendy Firmansyah, Mochamad Yusuf dan Tri Okta Argarini \\ Departemen Perencanaan Wilayah dan Kota, Fakultas Teknik Sipil, Perencanaan dan Kebumian, \\ Institut Teknologi Sepuluh Nopember (ITS) \\ e-mail: fendy.firmansyah@urplan.its.ac.id
}

\begin{abstract}
Abstrak- Dinamika pembangunan dan pertumbuhan penduduk yang sangat cepat berdampak pada berkurangnya keberadaan sawah di Provinsi Jawa Timur. Adanya alih fungsi lahan sawah akan menurunkan produksi bahan pangan yang dapat mengancam terwujudnya ketahanan pangan. Perlu adanya upaya pengendalian guna mencegah perubahan fungsi lahan pertanian ke non pertanian dan mencapai target ketahanan pangan. Penelitian ini dilakukan untuk merumuskan strategi pengendalian alih fungsi lahan sawah di Provinsi Jawa Timur dengan mengkaji kondisi alih fungsi lahan 2019, serta faktor pendorong terjadinya perubahan fungsi lahan. Metode pengambilan data dilakukan dengan survei instansional, studi literatur, dan diklarifikasi melalui Forum Group Discussion dengan perwakilan Pokja KP2B dan Dinas Pertanian seluruh Kabupaten dan Kota di Jawa Timur. Data yang didapat kemudian diolah dengan analisis spasial (overlay) menggunakan Software ArcGIS, analisis faktor (CFA) menggunakan SPSS, dan analisis deskriptif untuk merumuskan strategi. Dari hasil analisis, ditemukan bahwa luasan lahan sawah di Jawa Timur pada 2019 telah mengalami konversi/alih fungsi seluas 9817.54 Ha dari Peta Baku Sawah yang ditetapkan melalui SK Menteri ATR/BPN-RI No.399/Kep23.3/X/2018 tanggal 8 Oktober 2018. Konversi lahan sawah terbesar diakibatkan oleh banyaknya lahan sawah yang masuk kawasan hutan produksi, pengembangan lahan permukiman dan kawasan industri. Konversi tersebut disebabkan oleh beberapa variabel yaitu biaya input, biaya irigasi, biaya produksi, aksesibilitas wilayah, harga sewa, nilai produksi, harga jual dan harga lahan, jumlah petani, jumlah penduduk dan pertumbuhan ekonomi. Strategi pengendalian alih fungsi lahan pertanian secara umum meliputi pemberian bantuan dan insentif bagi petani, peningkatan kapasitas SDM di sektor pertanian, dan penguatan kebijakan di sektor pertanian.
\end{abstract}

Kata Kunci-Alih Fungsi, Ketahanan Pangan, Lahan Sawah.

\section{PENDAHULUAN}

$\mathrm{L}$ ahan sawah memiliki arti penting bagi masyarakat. Sawah menjadi media kegiatan untuk menanam bahan makanan pokok yang merupakan kebutuhan dasar setiap manusia, khususnya padi. Seiring kemajuan zaman teknologi dan perubahan pembangunan dan pertumbuhan penduduk secara dinamais menyebabkan terancamnya eksistensi lahan sawah. Masifnya alih fungsi kegiatan lahan sawah ke penggunaan lain menjadi salah satu masalah serius.

Hasil pengamatan oleh Badan Pusat Statistik, Badan Informasi Geospasial dan Lembaga Antariksa dan Penerbangan Nasional pada tahun 2018 menunjukkan terjadi penurunan luas sawah yang sangat signifikan di Indonesia. Luas lahan sawah yang mulanya 7,75 juta hektar pada 2013, menjadi 7,1 juta hektar pada 2018 [1]. Artinya terjadi penurunan seluas 650.000 hektar dalam waktu lima tahun. Konversi lahan ini terjadi akibat pengembangan industri, perumahan, dan infrastruktur [2].
Jawa Timur adalah salah satu provinsi potensial yang disebut Kementerian Pertanian memiliki lahan budidaya padi terbesar, yakni seluas 2,29 juta hektar [3]. Dibalik produktivitas yang tinggi terdapat penyusutan lahan pertanian yang masif menjadi permasalahan serius. Alih fungsi lahan pada tahun 2019 tercatat sebesar 9.597 hektar dengan 20 macam jenis alih fungsi lahan diantara yang terbesar seperti area pergudangan, area industri, hingga kawasan properti [4]. Misalnya, lahan pertanian di Kota Surabaya mengalami penyusutan hingga 300 hektar dalam 4 tahun terakhir yang digunakan untuk pembangunan perumahan, hotel, apartemen, dan perdagangan [5]. Bahkan, alih fungsi lahan yang masif untuk perumahan dan industri di Kabupaten Sidoarjo menyebabkan kabupaten yang dijuluki lumbung pangan Jawa Timur ini mengalami defisit beras pada tahun 2018 [6].

Perubahan fungsi lahan sawah yang menjadi salah satu unsur produksi pangan ini akan menyebabkan adanya penurunan produksi pangan, baik lokal maupun nasional [7]. Padahal, dalam RPJMD Jawa Timur 2019-2024 telah disebutkan bahwa Jawa Timur merupakan lumbung pangan dan pendukung terbesar terhadap ketersediaan pangan nasional. Disisi lain, Dewan Ketahanan Pangan, Kementerian Pertanian and World Food Programme (WFP) tahun 2015 telah merilis Peta Ketahanan dan Kerentanan Pangan Indonesia 2015 yang menyebutkan Kabupaten/ kota di Jawa Timur sebagian besar berada di prioritas 3 [8]. Artinya, wilayah Provinsi Jawa Timur memiliki ketahanan pangan yang cukup rentan. Maka, pengendalian alih kegiatan lahan pertanian perlu dilakukan agar ketahanan pangan tercapai [9].

Untuk mencegah peralihan fungsi lahan pertanian ke penggunaan lahan bukan pertanian, maka diperlukan suatu instrumen pengendalian berupa strategi pengendalian perubahan fungsi kegiatan lahan sawah di Provinsi Jawa Timur. Untuk mencapai tujuan tersebut maka diperlukan gambaran mengenai pola alih fungsi lahan sawah di Provinsi Jawa Timur yang diperoleh melalui hasil overlay peta baku sawah tahun 2018 dan peta tutupan lahan yang diperoleh dari Citra SPOT tahun 2019 melalui proses digitasi dan validasi lapangan. Selain itu, identifikasi fator-faktor pendorong terjadinya alih fungsi lahan sawah juga dilakukan melalui FGD yang hasilnya di analisis dengan menggunakan Teknik analisis CFA. Sehingga hasil dari analisis tersebut diharapkan dapat memberikan strategi untuk mengendalikan alih fungsi lahan sawah secara tepat dan komprehensif di Provinsi Jawa Timur. 


\section{METODE PENELITIAN}

\section{A. Teknik Pengumpulan Data}

Survei sekunder secara instansional untuk mendapatkan data spasial berupa peta lahan sawah wilayah Jawa Timur sesuai SK Menteri ATR/BPN-RI No. 399/Kep-23.3/X/2018 tanggal 8 Oktober 2018 serta peta tutupan lahan terbaru atau data citra SPOT tahun akusisi 2019. Survey sekunder juga dilakukan untuk merumuskan faktor-faktor pendorong terjadinya alih fungsi lahan melalui studi literatur jurnal.

Survei primer dengan Focus Group Discussion (FGD) untuk menangkap permasalahan yang dihadapi sektor pertanian, dan strategi penanganan yang sesuai. FGD dilakukan pada tahun 2019 dengan melibatkan pemangku kepentingan seperti perwakilan Pokja KP2B dan Dinas Pertanian seluruh Kabupaten dan Kota di Jawa Timur. Survey primer juga dilakukan melalui survey lapangan pada tahun 2019, guna memvalidasi peta tutupan lahan yang diperoleh dari hasil digitasi Citra SPOT tahun 2019.

\section{B. Variabel Penelitian}

Penelitian ini melibatkan 12 variabel yang dihasilkan dari studi literatur yaitu jumlah penduduk, pertumbuhan ekonomi, jumlah petani, produksi, harga jual komoditas, biaya irigasi, biaya input, pendapatan, harga sewa, harga lahan, nilai produksi, dan aksesibilitas wilayah [2][10][11][12][13]. Variabel-variabel tersebut diberi nilai oleh para stakeholder dalam FGD untuk mendapatkan faktor-faktor pembentuknya dan variabel apa yang dianggap kurang mewakili.

\section{Teknik Analisis Data}

Untuk merumuskan strategi pengendalian alih fungsi lahan sawah, dilakukan beberapa tahapan terstruktur berikut:

\section{Identifikasi Alih Fungsi Lahan Sawah (Faktual)}

Proses analisis dilakukan dengan menggunakan metode overlay peta melalui software ArGIS. Proses overlay memanfaatkan peta baku sawah SK Menteri ATR/BPN-RI No.399/Kep-23.3/X/2018 Tanggal 8 Oktober 2018 dan peta tutupan lahan tahun 2019. Tujuannya dari proses analisis ini adalah untuk mendapatkan hasil jumlah/luasan, sebaran alih fungsi lahan sawah dan peruntukan perubahan lahan sawah secara faktual di Provinsi Jawa Timur.

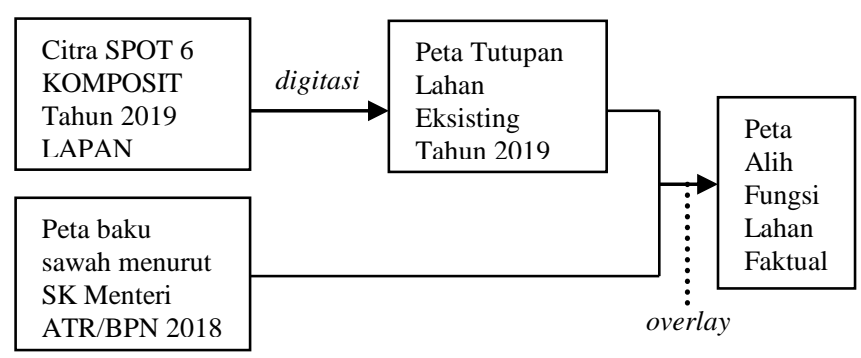

Gambar 1. Alur pikir identifikasi alih fungsi lahan sawah

\section{Identifikasi Faktor Pendorong Alih Fungsi Lahan}

Faktor-faktor penentu peralihan fungsi kegiatan lahan dihasilkan dari analisis faktor menggunakan Confirmatory Factor Analysis (CFA), yaitu metode analisis faktor pada kondisi dimana peneliti telah memiliki pengetahuan mengenai suatu faktor laten yang didasari teori, maupun hipotesa yang berkaitan dengan hubungan antara variabel yang diteliti dengan variabel laten [14]. Dibandingkan dengan analisis faktor yang lain, CFA dapat melakukan pengujian yang akan menjawab pertanyaan apakah variabel tertentu benar adanya atau secara akurat tergabung dalam sebuah konstruk [15]. Input analisis CFA pada penelitian ini adalah 12 variabel penentu alih fungsi lahan sawah yang didapat dari studi literatur. Sebelum melakukan CFA, 12 variabel tersebut divalidasi oleh stakeholder melalui FGD dengan cara memberikan penilaian dari 1 (tidak penting) hingga 4 (sangat penting).

Proses CFA terdiri dari 3 tahap. Tahap pertama adalah pemilihan indikator, tahap kedua dilakukan ekstraksi dan rotasi faktor, serta tahap ketiga adalah penamaan faktor. Pemilihan indikator yang layak dilakukan berdasarkan nilai Keiser-Meyers-Oklin (KMO) dan Anti-Image Matrics (MSA). KMO berfungsi untuk mengetahui tingkat kecocokan data untuk dijalankan analisis faktor. Sedangkan MSA berfungsi untuk melihat apakah sistem mampu membentuk faktor baru.

Tahap kedua adalah ekstraksi dan rotasi faktor untuk memperjelas interpretasi dan menghilangkan ambiguitas. Metode ekstraksi menggunakan Principal Component Analysis dengan rotasi Varimax. Principal Component Analysis dipilih dengan tujuan untuk mereduksi variabel terukur menjadi sekumpulan komponen kecil dengan mengekstrak varians maksimum dari kumpulan data [16]. Varimax digunakan sebab membuat faktor-faktor independen. Penentuan jumlah faktor yang terbentuk menggunakan Kaiser's Criterion dengan kriteria nilai eigen values lebih dari 1. Nilai Eigen merupakan total varians yang dapat dijelaskan oleh setiap faktor. Varians adalah keragaman atau keunikan yang ada di setiap variabel yang diamati.

Tahap ketiga yaitu penamaan faktor untuk pengelompokan indikator yang terbentuk. Penamaan faktor dilakukan dengan nama yang dapat mewakili faktor-faktor yang tebentuk.

\section{Strategi Pengendalian Alih Fungsi Lahan Sawah}

Ketiga, perumusan strategi pengendalian alih fungsi lahan dilakukan dengan menghimpun masukan dari stakeholder dalam FGD yaitu perwakilan Pokja KP2B dan Dinas Pertanian pada semua kabupaten dan kota Jawa Timur. Dalam upaya untuk melihat keterkaitan strategi untuk mengendalikan alih fungsi lahan pertanian dengan kebijakan dalam skala nasional maka hasil diskusi tersebut dirumuskan kembali dengan mengacu pada Rencana Strategis Kementerian Pertanian 2015-2019. Berikut adalah alur penelitian dimulai dari sasaran 1 hingga sasaran 3 yaitu untuk merumuskan strategi untuk pengendalian peralihan fungsi lahan sawah Prrovinsi Jawa Timur.

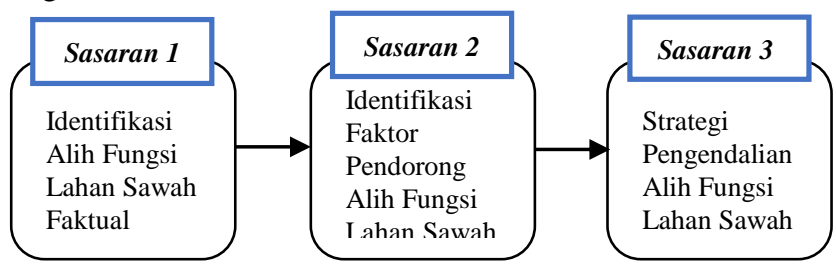

Gambar 2. Alur Penelitian

\section{GAMBARAN UMUM WILAYAH}

\section{A. Gambaran Umum Wilayah Penelitian}

Jawa Timur memiliki luas wilayah mencapai kurang lebih 4.779.975 Ha dan terbagi atas 29 wilayah kabupaten dan 9 
kota. Berdasarkan tutupan lahannya, Provinsi Jawa Timur dapat dikategorisasikan menjadi dua, yaitu lahan budidaya dan lahan lindung. Kawasan lindung memiliki luas sekitar 578.374 hektar atau $12,10 \%$ dari luas total Provinsi Jawa Timur. Sedangkan lahan budidaya mencapai ukuran 4.201.403,70 hektar yakni 87,90\% dari luas keseluruhan Jawa Timur (RTRW Provinsi Tahun 2011-2031).

Perubahan rasio penggunaan lahan di Jawa Timur memperlihatkan adanya tren penurunan luas kawasan pertanian. Menurut data baku sawah yang dikeluarkan Menteri ATR/BPN melalui SK Menteri ATR/BPN-RI No.399/Kep-23.3/X/2018 Tanggal 8 Oktober 2018, Provinsi Jawa Timur memiliki luas sawah sebesar 1.368.563,014 Ha seperti dapat dilihat pada Gambar 3 di bawah. Penyebab alih fungsi lahan dengan luasan yang cukup tinggi untuk industri dan permukiman serta perumahan skala besar/developer didorong oleh ketersediaan prasarana [17].

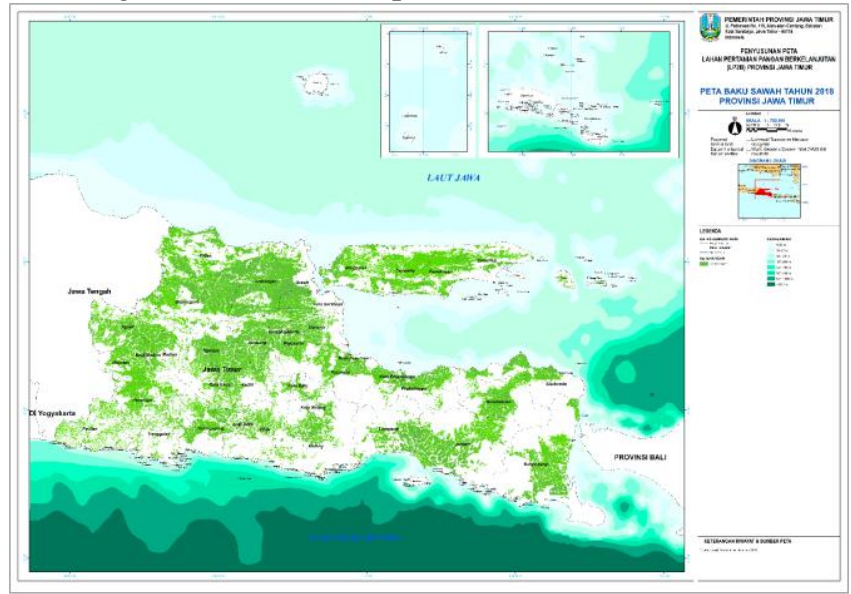

Gambar 3. Peta Baku Sawah Jawa Timur Tahun 2018 berdasarkan Kementerian ATR/BPN dan Kementerian Pertanian melalui SK Menteri ATR/BPN-RI No. 399/Kep-23.3/X/2018

Disisi lain, jika dilihat dari struktur ekonominya pada 2016, Provinsi Jawa Timur dipengaruhi oleh 5 (lima) sektor utama yaitu sektor industri pengolahan, sektor perdagangan besar dan eceran, sektor pertanian, sektor konstruksi dan sektor informasi-komunikasi. Sektor pertanian menempati urutan ke 3 penyumbang PDRB tertinggi sehingga dipandang sebagai sebuah potensi [18]. Dengan alasan itulah pentingnya pengendalian pemanfaatan penggunaan lahan terbangun guna mengurangi konversi lahan irigasi teknis. Berikut adalah peta tutupan lahan Provinsi Jawa Timur Tahun 2019.

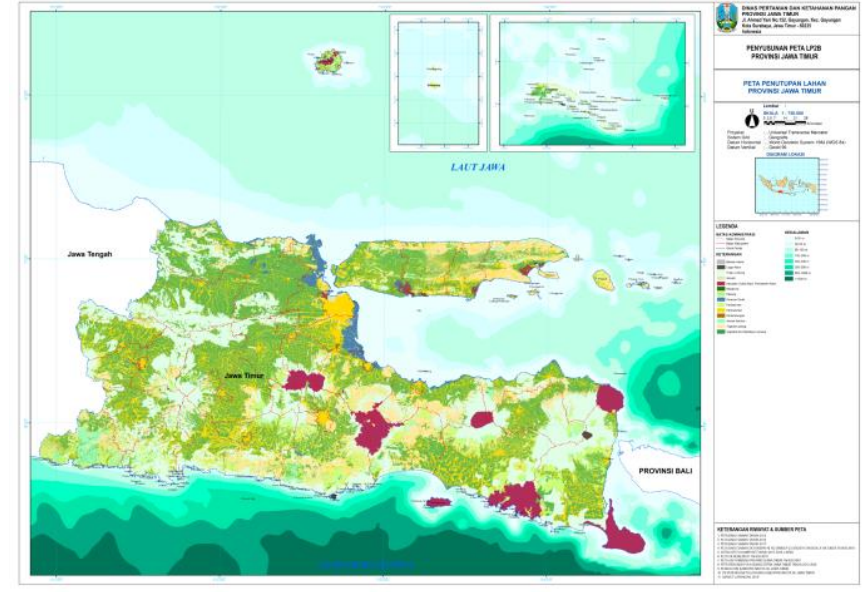

Gambar 4. Peta Tutupan Lahan Provinsi Jawa Timur Tahun 2019

\section{HASIL DAN DISKUSI}

\section{B. Mengidentifikasi Alih Fungsi Lahan Sawah}

Hasil analisis overlay peta baku sawah SK Menteri ATR/BPN-RI No.399/Kep-23.3/X/2018 Tanggal 8 Oktober 2018 dengan citra satelit terbaru/tutupan lahan terbaru menggunakan software ArGIS, diperoleh hasil baku sawah faktual tahun 2019. Tabel berikut menunjukkan hasil analisis yang memperlihatkan bahwa terdapat konversi lahan sebesar 9817.69 hektar pada tahun 2019.

Tabel 1.

Perbandingan Luas Baku Sawah 2018 dengan Luas Sawah Faktual 2019 di Provinsi Jawa Timur

\begin{tabular}{|c|c|c|c|c|}
\hline \multirow[b]{2}{*}{ No } & \multirow[b]{2}{*}{$\begin{array}{c}\text { Kabupaten/ } \\
\text { Kota }\end{array}$} & \multicolumn{3}{|c|}{ Luas (Hektar) } \\
\hline & & $\begin{array}{c}\text { Baku Sawah } \\
\text { SK } \\
\text { ATR/BPN }\end{array}$ & $\begin{array}{c}\text { Sawah } \\
\text { Faktual }\end{array}$ & Konversi \\
\hline 1 & Bangkalan & 36032,61 & 35885,40 & 147,20 \\
\hline 2 & Banyuwangi & 69790,55 & 69740,35 & 50,20 \\
\hline 3 & Blitar & 33304,40 & 33290,20 & 14,19 \\
\hline 4 & Bojonegoro & 89231,90 & 88098,47 & 1133,43 \\
\hline 5 & Bondowoso & 39649,10 & 39639,85 & 9,25 \\
\hline 6 & Gresik & 43568,26 & 43246,90 & 321,35 \\
\hline 7 & Jember & 85833,01 & 85773,12 & 59,89 \\
\hline 8 & Jombang & 45945,35 & 45507,55 & 437,80 \\
\hline 9 & Kediri & 45481,50 & 45315,38 & 166,12 \\
\hline 10 & Kota Batu & 3951,21 & 3506,28 & 444,94 \\
\hline 11 & Kota Blitar & 915,86 & 909,28 & 6,57 \\
\hline 12 & Kota Kediri & 2653,93 & 2592,36 & 61,57 \\
\hline 13 & Kota Madiun & 1076,81 & 1046,14 & 30,67 \\
\hline 14 & Kota Malang & 1237,01 & 1195,52 & 41,48 \\
\hline 15 & Kota Mojokerto & 455,66 & 447,58 & 8,08 \\
\hline 16 & Kota Pasuruan & 1084,14 & 1035,07 & 49,07 \\
\hline 17 & Kota Probolinggo & 2373,38 & 2275,53 & 97,86 \\
\hline 18 & Lamongan & 105049,14 & 103154,94 & 1894,19 \\
\hline 19 & Lumajang & 36626,96 & 36527,85 & 99,11 \\
\hline 20 & Madiun & 33094,94 & 32069,95 & 1024,99 \\
\hline 21 & Magetan & 27155,15 & 27153,34 & 1,81 \\
\hline 22 & Malang & 45733,37 & 45647,92 & 85,45 \\
\hline 23 & Mojokerto & 37392,67 & 37204,27 & 188,41 \\
\hline 24 & Nganjuk & 48264,37 & 47444,79 & 819,58 \\
\hline 25 & Ngawi & 50904,11 & 50495,16 & 408,95 \\
\hline 26 & Pacitan & 12696,54 & 12695,47 & 1,08 \\
\hline 27 & Pamekasan & 27353,94 & 26994,00 & 359,94 \\
\hline 28 & Pasuruan & 37812,95 & 37636,44 & 176,51 \\
\hline 29 & Ponorogo & 35650,20 & 35648,70 & 1,50 \\
\hline 30 & Probolinggo & 40571,42 & 40245,57 & 325,85 \\
\hline 31 & Sampang & 38494,57 & 38437,09 & 57,48 \\
\hline 32 & Sidoarjo & 23059,90 & 22727,59 & 332,31 \\
\hline 33 & Situbondo & 33936,03 & 33920,09 & 15,94 \\
\hline
\end{tabular}




\begin{tabular}{llccc}
\hline \hline & & \multicolumn{3}{c}{ Luas (Hektar) } \\
No & $\begin{array}{c}\text { Kabupaten/ } \\
\text { Kota }\end{array}$ & $\begin{array}{c}\text { Baku Sawah } \\
\text { SK } \\
\text { ATR/BPN }\end{array}$ & $\begin{array}{c}\text { Sawah } \\
\text { Faktual }\end{array}$ & Konversi \\
& & 35890,52 & 35592,05 & 298,47 \\
\hline 34 & Sumenep & 2232,17 & 1978,51 & 253,66 \\
35 & Kota Surabaya & 12061,79 & 12050,00 & 11,79 \\
36 & Trenggalek & 75441,17 & 75066,25 & 374,92 \\
37 & Tuban & 25666,53 & 25660,46 & 6,07 \\
38 & Tulungagung & $\mathbf{1 2 8 7 6 7 3 , 1 1}$ & $\mathbf{1 2 7 7 8 5 5 , 4 2}$ & $\mathbf{9 8 1 7 , 6 9}$ \\
\hline \hline & Total & & & \\
\hline
\end{tabular}

Dari hasil tersebut dapat diketahui bahwa proporsi terbesar terjadinya konversi lahan sawah di Jawa Timur terjadi di Kabupaten Lamongan dengan prosentase konversi sebanyak $19.29 \%$ atau seluas 1894.19 hektar dari total luas konversi yang terjadi. Selain itu konversi terbesar juga terjadi di Kabupaten Bojonegoro dengan prosentase konversi sebesar $11.54 \%$ atau seluas 1133.43 hektar dari luas konversi lahan sawah di Jawa Timur yang seluas 9817.69 hektar.

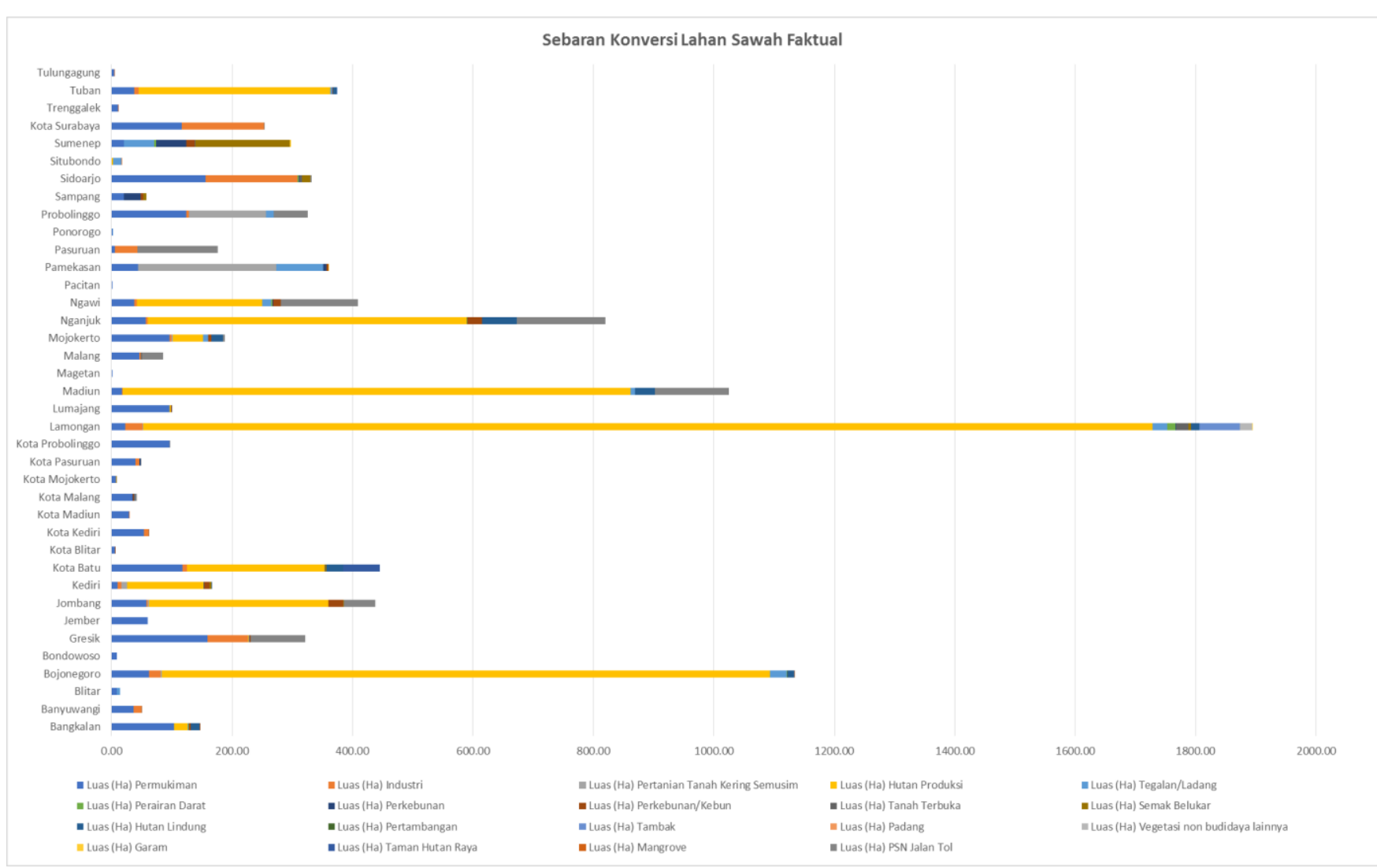

Gambar 5. Diagram Sebaran Konversi Lahan Sawah Faktual 2019

Diagram 5. menunjukkan bahwa konversi lahan sawah di area hutan produksi terbesar berada di Kabupaten Lamongan dengan luas total luas sebesar 1676,09 hektar, dan di Kabupaten Bojonegoro sebesar 1009,68 hektar (melalui proses validasi dengan Peta Hutan Produksi diperoleh dari SK Kemenhut tahun 2019). Selanjutnya, konversi lahan sawah ke permukiman terbesar berada di Kabupaten Gresik sebesar 159,78 hektar, Kabupaten Sidoarjo sebesar 155,97 hektar, Kabupaten Probolinggo sebesar 123,80 hektar, Kota Batu sebesar 117,57 hektar, dan Kota Surabaya sebesar 116,37 hektar.

Luas lahan sawah yang terkonversi akibat perkembangan kawasan industri terbesar terjadi di Kabupaten Sidoarjo sebesar 152,96 hektar, Kota Surabaya sebesar 136,71 hektar, dan Kabupaten Gresik sebesar 66,55 hektar, sementara Kabupaten Lamongan sebesar 29,40 hektar. Sebaran konversi lahan sawah ke penggunaan lain secara lebih detail dapat di jelaskan melalui tabel konversi lahan sawah yang sudah disajikan sebelumnya.

Sedangkan, luas lahan sawah yang terkonversi akibat perkembangan kawasan industri terbesar terjadi di Kabupaten Sidoarjo sebesar 152,96 hektar, Kota Surabaya

sebesar 136,71 hektar, Kabupaten Gresik sebesar 66,55 hektar, dan Kabupaten Lamongan sebesar 29,40 hektar.

Total lahan seluas 9817.54 Ha yang tersebar di seluruh wilayah di Jawa Timur. Sebaran peralihan alih guna lahan sawah di kawasan Jawa Timur tahun 2019 dituangkan dalam peta dibawah ini.

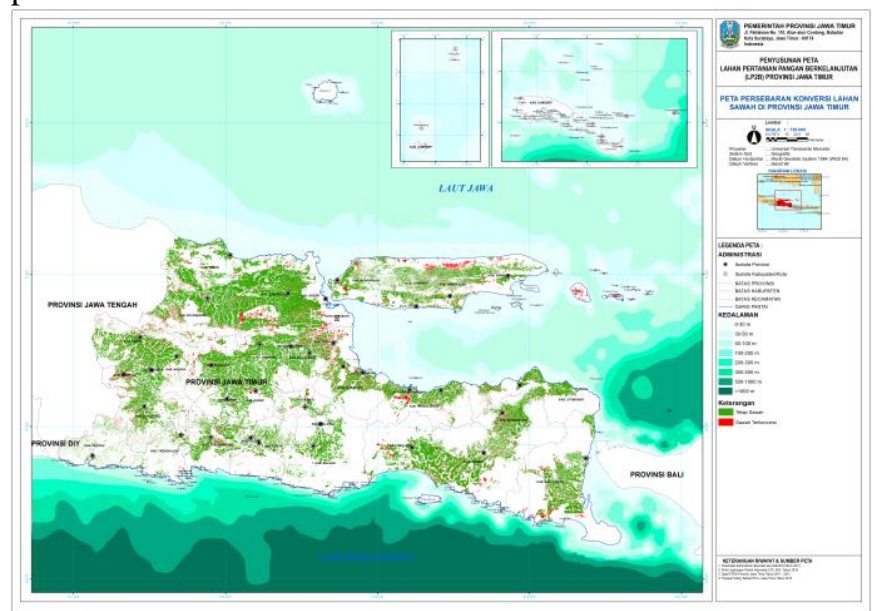

Gambar 6. Peta Sebaran Alih Fungsi Lahan Sawah di Provinsi Jawa Timur Tahun 2019 


\section{Mengidentifikasi Faktor Pendorong Terjadinya Alih Fungsi Lahan Sawah}

Hasil pendekatan statistik menggunakan Confirmatory Faktor Analysis terhadap 12 variabel yang telah disusun dari studi literatur berupa 3 faktor pendorong terjadinya alih fungsi lahan sawah. Faktor tersebut adalah faktor produksi, faktor pendapatan, dan faktor demografi.

- Kaiser-Meyer-Olkin Measure of Sampling Adequacy (KMO MSA)

Agar dapat melakukan pengukuran level interkorelasi antara variabel dan kecocokan data yang ada untuk analisis faktor, sebelumnya perlu diperhatikan nilai KMO. Nilainya dari $0-1$. Nilai diharuskan $>0.50$ sehingga dapat menganalisis faktor. Nilai KMO pada riset 0.615 artinya data memadai untuk analisis faktor.

\section{- Anti Image Matrices (MSA)}

Nilai Anti-Image Matrics digunakan untuk mengetahui hubungan yang terpola dalam data yang dianalisis. Proses analisis dapat dilanjutkan ketika nilai Anti-Image Matrics $\mathrm{p}>0.5$. Apabila nilai Anti-Image Matrics $\mathrm{p}<0.5$, maka variabel perlu direduksi untuk meningkatkan akurasi model. Dari matriks yang dihasilkan, dapat diketahui bahwa variabel pendapatan nilai Anti Image Correlation < 0.5, sehingga perlu untuk dieliminasi atau dianggap bukan menjadi variabel berpengaruh terhadap alih fungsi lahan pertanian. Berikut disajikan data Anti-Image Matrics.

Tabel 2.

\begin{tabular}{clc}
\multicolumn{3}{c}{ Hasil Penghitungan Matriks Anti-Image (Iterasi 1) } \\
\hline \hline No & \multicolumn{1}{c}{ Variabel } & MSA \\
\hline 1 & Jumlah Penduduk & 0.562 \\
2 & Pertumbuhan Ekonomi & 0.695 \\
3 & Jumlah Petani & 0.560 \\
4 & Produksi & 0.616 \\
5 & Harga Jual Komoditas & 0.753 \\
6 & Biaya Irigasi & 0.735 \\
7 & Biaya Input & 0.679 \\
$\mathbf{8}$ & Pendapatan & $\mathbf{0 . 4 5 8}$ \\
9 & Harga Sewa & 0.538 \\
10 & Harga Lahan & 0.656 \\
11 & Nilai Produksi & 0.672 \\
12 & Aksesibilitas Wilayah & 0.663 \\
\hline \hline
\end{tabular}

Setelah variabel pendapatan dieliminasi, maka analisis CFA kembali dilakukan dengan input 11 variabel. Dalam iterasi kedua, nilai KMO mengalami peningkatan dari 0.615 menjadi 0.664. Nilai Anti Image Correlation dari 11 variabel terpilih berada di atas 0.5 , sehingga CFA untuk 11 variabel dapat dilanjutkan. Tabel berikut menunjukkan Matriks Anti Image pada iterasi kedua.

Tabel 3.

\begin{tabular}{clc}
\multicolumn{3}{c}{ Hasil Penghitungan Matriks Anti-Image (Iterasi 2) } \\
\hline No & \multicolumn{1}{c}{ Variabel } & MSA \\
\hline 1 & Jumlah Penduduk & 0.726 \\
2 & Pertumbuhan Ekonomi & 0.670 \\
3 & Jumlah Petani & 0.585 \\
4 & Produksi & 0.813 \\
5 & Harga Jual Komoditas & 0.569 \\
6 & Biaya Irigasi & 0.753 \\
7 & Biaya Input & 0.652 \\
8 & Harga Sewa & 0.591 \\
9 & Harga Lahan & 0.650 \\
10 & Nilai Produksi & 0.555 \\
11 & Aksesibilitas Wilayah & 0.718 \\
\hline
\end{tabular}

- Total Variance Explained

SPSS akan mengelompokkan 11 variabel menjadi tiga faktor berdasar nilai eigen value $>1$, faktor 1 eigen value 4.433, faktor 2 eigen value 1.386, dan faktor 3 eigen value 1.360. Dari tampilan output SPSS terlihat bahwa faktor 1 menjelaskan variasi sebesar $40.296 \%$, faktor 2 menjelaskan variasi sebesar $12.599 \%$, dan faktor 3 menjelaskan variasi sebesar $12.364 \%$. Hasil perhitungan total variance berikut.

Tabel 4.

Hasil Penghitungan Total Variance

\begin{tabular}{cccc}
\hline \hline No & \multicolumn{3}{c}{ Initial Eigenvalues } \\
\hline & Total & \% of Variance & Cumulative \% \\
1 & 4.433 & 40.296 & 40.296 \\
2 & 1.386 & 12.599 & 52.895 \\
3 & 1.360 & 12.364 & 65.259 \\
\hline \hline
\end{tabular}

- Rotated Component Matrix

Berdasarkan hasil rotasi, didapatkan bahwa Faktor 1 terdiri atas variabel biaya input, biaya irigasi dan produksi. Faktor 2 terdiri atas variabel aksesibilitas wilayah, harga sewa, nilai produksi, harga jual dan harga lahan. Faktor 3 terdiri atas variabel jumlah petani, jumlah penduduk dan pertumbuhan ekonomi. Sehingga alih fungsi lahan pertanian disebabkan oleh faktor produksi, faktor pendapatan, dan faktor demografi.

Tabel 5.

Hasil Penghitungan Rotated Component Matrix

\begin{tabular}{|c|c|c|c|c|}
\hline \multirow[t]{2}{*}{ No } & \multirow[t]{2}{*}{ Variabel } & \multicolumn{3}{|c|}{ Faktor } \\
\hline & & Produksi & Pendapatan & Demografi \\
\hline 1 & $\begin{array}{l}\text { Jumlah } \\
\text { Penduduk }\end{array}$ & 0.199 & -0.032 & 0.820 \\
\hline 2 & $\begin{array}{l}\text { Pertumbuhan } \\
\text { Ekonomi }\end{array}$ & 0.034 & 0.330 & 0.645 \\
\hline 3 & Jumlah Petani & 0.428 & 0.005 & 0.662 \\
\hline 4 & Produksi & 0.752 & 0.146 & 0.395 \\
\hline 5 & $\begin{array}{l}\text { Harga Jual } \\
\text { Komoditas }\end{array}$ & 0.008 & 0.605 & 0.569 \\
\hline 6 & Biaya Irigasi & 0.797 & 0.265 & 0.172 \\
\hline 7 & Biaya Input & 0.910 & 0.093 & 0.057 \\
\hline 8 & Harga Sewa & 0.372 & 0.578 & 0.197 \\
\hline 9 & Harga Lahan & 0.001 & 0.692 & 0.212 \\
\hline 10 & $\begin{array}{l}\text { Nilai } \\
\text { Produksi }\end{array}$ & 0.237 & 0.748 & -0.14 \\
\hline 11 & $\begin{array}{l}\text { Aksesibilitas } \\
\text { Wilayah }\end{array}$ & 0.531 & 0.595 & 0.06 \\
\hline
\end{tabular}

\section{- Temuan Penelitian}

Selain variabel-variabel dari tinjauan literatur, variabelvariabel juga dihimpun dari proses FGD bersama perwakilan Dinas Pertanian dari Kabupaten dan Kota dalam lingkup Provinsi Jawa Timur. Variabel-variabel tersebut adalah rendahnya regenerasi petani muda, musim tanam, insentif yang diberikan petani, teknologi informasi dan sarana prasarana, lokasi lahan sawah, sosial budaya (hukum waris), kepemilikan lahan, pengembangan industri, rendahnya penjualan hasil panen, degradasi lingkungan, perizinan, akses permodalan, dinamika penyediaan infrastruktur, pajak bumi dan bangunan, pengetahuan petani terhadap penggunaan ALSIN, dan kurangnya pedoman operasional pengendalian.

Berdasarkan variabel-variabel tersebut, maka secara persepsional dapat dikategorikan dalam faktor kebijakan, faktor pengetahuan dan inovasi, faktor infrastruktur, dan faktor alam. Tahapan selanjutnya adalah menggali strategi 
penanganan alih fungsi lahan pertanian. Strategi yang dirumuskan didasarkan pada variabel terpilih dan faktorfaktor hasil pengelompokan variabel.

\section{Strategi Pengendalian Alih Fungsi Lahan Pertanian}

Strategi dirumuskan melalui proses FGD bersama perwakilan dari Kabupaten dan Kota dalam lingkup Provinsi Jawa Timur dan tim Pokja KP2B. Strategi yang dihasilkan juga disesuaikan dengan Rencana Strategis Kementerian Pertanian. Dari analisis sebelumnya, dihasilkan 3 faktor penentu alih fungsi lahan yaitu faktor produksi, faktor pendapatan, dan faktor demografi. Masing-masing faktor penentu menghasilkan strategi berikut.

Tabel 6.

Strategi Pengendalian Alih Fungsi Lahan Pertanian Berdasarkan Faktor Penentu Alih Fungsi Lahan

\begin{tabular}{|c|c|}
\hline Variabel & Strategi \\
\hline \multicolumn{2}{|c|}{ Faktor Produksi } \\
\hline Produksi & $\begin{array}{l}\text { Pengembangan dan perluasan } \\
\text { distribusi bantuan logistik benih/bibit, } \\
\text { pupuk, alat dan mesin pertanian } \\
\text { (alsintan) secara merata dan tepat } \\
\text { waktu, sesuai dengan masa tanam. }\end{array}$ \\
\hline Biaya input & $\begin{array}{l}\text { Peningkatan bantuan pembiayaan } \\
\text { produksi pertanian, serta menjamin } \\
\text { kemudahan akses petani terhadap } \\
\text { bantuan bibit, pupuk, alat dan mesin } \\
\text { pertanian (alsintan) yang murah dan } \\
\text { berkualitas. }\end{array}$ \\
\hline Biaya irigasi & $\begin{array}{l}\text { Peningkatan kemudahan akses } \\
\text { terhadap pasokan air irigasi melalui } \\
\text { perluasan daerah irigasi } \\
\text { pembangunan } \\
\text { penambahan jaringan irigasi tersier. }\end{array}$ \\
\hline \multicolumn{2}{|c|}{ Faktor Pendapatan } \\
\hline Harga sewa & $\begin{array}{l}\text { Memperbaiki mekanisme pemberian } \\
\text { insentif berupa keringan pajak lahan } \\
\text { untuk kegiatan pertanian pangan dan } \\
\text { retribusi untuk kegiatan non pertanian } \\
\text { pangan di lahan sawah. }\end{array}$ \\
\hline Harga lahan & $\begin{array}{l}\text { Menjaga stabilitas harga lahan } \\
\text { pertanian pangan melalui instrumen } \\
\text { inssntif dan disinsentif, peningkatan } \\
\text { hasil produksi pertanian pangan, dan } \\
\text { memperketat proses perijinan non } \\
\text { pertanian pangan di lahan sawah. }\end{array}$ \\
\hline Harga jual komoditas & $\begin{array}{l}\text { Penguatan jaringan pasar produk } \\
\text { pertanian pangan melalui peningkatan } \\
\text { akses petani terhadap pasar domestik } \\
\text { maupun internasional, dan stabilisasi } \\
\text { harga dasar hasil pertanian. }\end{array}$ \\
\hline Aksesibilitas wilayah & $\begin{array}{l}\text { Pengembangan dan peningkatan } \\
\text { akses transportasi menuju sentra- } \\
\text { sentra produksi pertanian pangan } \\
\text { maupun pasar. }\end{array}$ \\
\hline Nilai Produksi & $\begin{array}{l}\text { Penguatan } \begin{array}{l}\text { produk } \\
\text { peningkatan mutu }\end{array} \text { hasil } \begin{array}{l}\text { melalui } \\
\text { produksi } \\
\text { pertanian. }\end{array} \\
\end{array}$ \\
\hline \multicolumn{2}{|c|}{ Faktor Demografi } \\
\hline $\begin{array}{l}\text { Jumlah penduduk / rumah } \\
\text { tangga }\end{array}$ & $\begin{array}{l}\text { Pelibatan peran serta masyarakat } \\
\text { dalam proses perencanaan, } \\
\text { pelaksanaan dan pengawasan } \\
\text { program-program di sektor pertanian } \\
\text { pangan. Serta sosialisasi secara rutin } \\
\text { akan pentingnya lahan pertanian } \\
\text { pangan terhadap ketahanan pangan } \\
\text { daerah. }\end{array}$ \\
\hline Pertumbuhan ekonomi & $\begin{array}{l}\text { Mempercepat proses penetapan LP2B } \\
\text { di daerah, serta meningkatkan } \\
\text { kapasitas sumber daya aparatur dalam }\end{array}$ \\
\hline
\end{tabular}

\begin{tabular}{ll}
\hline Variabel & \multicolumn{2}{c}{ Strategi } \\
& $\begin{array}{l}\text { pengawasan alih fungsi lahan } \\
\text { pertanian pangan. }\end{array}$ \\
\hline Jumlah Petani & $\begin{array}{l}\text { Penguatan kelembagaan melalui } \\
\text { pelibatan aktif kelompok tani } \\
\text { (gapoktan) dalam program pertanian }\end{array}$ \\
& pangan dan peningkatan kapasitas \\
& SDM petani melalui penyuluhan dan \\
& pelatihan keterampilan. \\
\hline
\end{tabular}

\section{KESIMPULAN/RINGKASAN}

Strategi pengendalian konversi guna lahan sawah dapat dilakukan melalui kajian kondisi alih guna lahan sawah, serta faktor pendorong terjadinya perubahan fungsi kegiatan lahan sawah. Berdasarkan hasil kajian teridentifikasi luas sawah faktual di Jawa Timur seluas 1.277.855,42 hektar dari total luas sawah baku tahun 2018 seluas 1.287.676,42 hektar. Dimana konversi lahan sawah terbesar diakibatkan karena banyak lahan sawah yang masuk kawasan hutan produksi, pengembangan lahan permukiman dan kawasan industri. Faktor penyebab alih fungsi lahan sawah yaitu faktor produksi, faktor pendapatan, dan faktor demografi. Dalam perumusan strategi untuk mengendalikan alih fungsi lahan pertanian, secara umum strategi yang didapatkan meliputi pemberian bantuan dan insentif bagi petani atau pelaku di sektor pertanian, peningkatan kapasitas SDM di bidang pertanian, dan penguatan kebijakan yang berkaitan dengan sektor pertanian. Adapun rekomendasi dalam penelitian ini berupa penetapan lahan pertanian pangan berkelanjutan (LP2B) harus segera dilakukan sebagai upaya untuk memberikan kepastian hukum di sektor pertanian pangan dan sabagai salah satu alat untuk mengendalikan laju koversi lahan pertanian khususnya sawah di daerah.

\section{UCAPAN TERIMA KASIH}

Penulis mengucapkan terima kasih kepada Dinas Pertanian dan Ketahanan Pangan Provinsi Jawa Timur yang telah mendukung secara finansial jalannya penelitian ini. Serta perwakilan Pokja KP2B dan Dinas Pertanian di Jawa Timur yang bersedia terlibat dalam proses FGD.

\section{DAFTAR PUSTAKA}

[1] CNN, "BPS Sebut Luas Lahan Pertanian Kian Menurun," 2018.

[2] N. Ashari, "Tinjauan tentang Alih Fungsi Lahan Sawah ke Non Sawah dan Dampaknya di Pulau Jawa," Forum Penelit. Agro Ekon. 2016, doi: 10.21082/fae.v21n2.2003.83-98.

[3] Walhi, "Alih Fungsi Lahan Produktif Mengancam Keberlangsungan Lingkungan Hidup," 2019. http://walhijatim.or.id/2018/09/alihfungsi-lahan-produktif-mengancam-keberlansungan-lingkunganhidup/ (accessed Mar. 18, 2021).

[4] S. Radar, "9.597 Hektare Sawah di Jatim Berubah Jadi Proyek Properti," 2020.

[5] Republika.co.id, "Lahan Pertanian di Surabaya Menyusut," 2016.

[6] Tabloidsinartani, "Sidoarjo, Panen di Tengah Himpitan Alih Fungsi Lahan," 2017.

[7] A. Nurpita, L. Wihastuti, and I. Y. Andjani, "Dampak Alih Fungsi Lahan Sawah terhadap Ketahanan Pangan Beras," J. Gama Soc., 2018.

[8] WFP and D. K. Pangan, "Peta Ketahanan dan Kerentanan Pangan Indonesia 2015: Versi Rangkuman," 2015.

[9] N. K. Dewi and I. Rudiarto, "Identifikasi Alih Fungsi Lahan Pertanian dan Kondisi Sosial Ekonomi Masyarakat Daerah Pinggiran di Kecamatan Gunungpati Kota Semarang," J. Wil. dan Lingkung., vol. 1, no. 2, p. 175, 2013, doi: 10.14710/jwl.1.2.175-188. 
[10] E. W. Pradana and A. Pamungkas, "Pengendalian Konversi Lahan Pertanian Pangan Menjadi Non Pertanian Berdasarkan Preferensi Petani di Kecamatan Wongsorejo , Kabupaten," J. Tek. ITS, pp. 1-5, 2011, doi: 10.12962/j23373539.v2i2.3923.

[11] A. F. Sunartomo, "Alih Fungsi Lahan Pertanian dan Produksi Pangan di Kabupaten Jember," J. Sos. Ekon. Pertan., vol. 8, no. 22, pp. 4758, 2015, [Online]. Available: http://jurnal.unej.ac.id/index.php/JSEP/article/view/3750.

[12] M. Kurniasari and P. G. Ariastita, "Faktor - Faktor yang Mempengaruhi Alih Fungsi Lahan Pertanian Sebagai Upaya Prediksi Perkembangan Lahan Pertanian di Kabupaten Lamongan," J. Tek. Pomits, vol. 3, no. 2, pp. C119-C124, 2014, [Online]. Available: http://www.ejurnal.its.ac.id/index.php/teknik/article/view/7237.

[13] I. R. Ridwan, "FAKTOR-FAKTOR PENYEBAB DAN DAMPAK KONVERSI LAHAN PERTANIAN,” J. Geogr. Gea, 2016, doi: 10.17509/gea.v9i2.2448.

[14] K. G. Jöreskog, S. Dag., and J. Magidson, "Advances in factor analysis and structural equation models." Abt Books, 1979.

[15] B. Simamora, "Confirmatory Factor Analysis," 2018. https://www.bilsonsimamora.com/multivariat/confirmatory-factoranalysis/.

[16] H. S. Park, R. Dailey, and D. Lemus, "The Use of Exploratory Factor Analysis and Principal Components Analysis in Communication Research," Hum. Commun. Res., vol. 28, no. 4, pp. 562-577, Oct. 2002, doi: 10.1111/j.1468-2958.2002.tb00824.x.

[17] Hidayat, "Analisis Konversi Lahan Sawah di Propinsi Jawa Timur," J-Sep, vol. 2, no. 3, pp. 48-58, 2008, [Online]. Available: http://jurnal.unej.ac.id/index.php/JSEP/article/view/431.

[18] BPS, “Jawa Timur Province in Figures 2016," Bps, 2016. 